\title{
URUGUAY: 1876-1880. LATORRE, VARELA Y VERA
}

Juan Jose Arteaga Saenz

Hay momentos en la vida de las naciones y de los pueblos en que la historia parece acelerarse, hay etapas cruciales en la que se juega el destino de una comunidad por muchas décadas, hay tiempos cimentadores del futuro.

Todo esto se da en el Uruguay entre 1876 y 1880 , convirtiendo a este período en un lustro decisivo en el processo histórico del país.

Esta obra, obra fundamental en cuanto consolidará la tan discutida existencia del Uruguay, se da en torno a tres figuras: Latorre, Varela y Vera, que representan a tres fuerzas distintas, el estado, la educación y la iglesia.

Distintas no significa necesariamente opuestas. Pero ya veremos como estas tres fuerzas se verán envueltas en el campo de las luchas filosóficas de la segunda mitad del siglo XIX.

\section{I}

\section{EL URUGUAY ANTES DE 1876}

\section{A) El estado}

La República Oriental del Uruguay, nacida a la vida estatal en 1830, después de largos años de lucha por su autonomía, había tenido que superar en estas casi cinco décadas que la separan de 1876, numerosas revoluciones, levantamientos e intervenciones extranjeras. Baste recordar las mas importantes por la conmoción que produjeron en la vida social y económica del país: la "guerra grande" (1839-1852), la "cruzada libertadora" del gral. Venancio Flores (1863-1865) y la "revolución de las lanzas" (1870-1872) acaudillada por el gral. Timoteo Aparicio.

Todos estos sucesos, sumados a los enfrentamientos entre militares-caudillos de las dos divisas "blanca" y "colorada"; a las luchas entre doctores y caudillos, es decir entre la ciudad-puerto y el interior, entre la burguesía liberal y el gaucho; y últimamente entre "principistas" fusionistas y los partidarios de la política de partido o de divisa, hicieron al estado uruguayo, que por otra parte padecía una crónica carencia de recursos, intrínsecamente débil en sus cincuenta primeros años de vida. 
Los intentos realizados para reordenar al país, política y económicamente, por presidencias del gral. Manuel Oribe (1835-1838) y de Bernardo Prudencio $\mathrm{B}_{\mathrm{e}}$ (1860-1864), o los intentos de afirmación nacional como la política de "fusión"
saron ante la imposibilidad del estado de hacer valer su autoridad.

Es que hasta 1876 , salvo que coincida el caudillo principal con la presidencia de República, el estado prácticamente no cuenta como factor de poder.

Aparentemente la existencia de una Constitución, de un presidente de la Repúbliz asesorado por sus ministros, de una vida parlamentaria a veces brillante, de una ciude capital que seguía la moda europea, nos indican la presencia de un estado moderno civilizado al mejor estilo del liberalismo del siglo XIX.

Pero todo esto no era mas que una fachada, un recubrimiento formal. $\mathrm{Si}$ e presidente carecía del apoyo de los caudillos o se le conocía débil aparecía el desorden la anarquía, el país semifeudal se implantaba como la auténtica expresión de la nació toda.

Podemos afirmar que hasta 1876 no existieron, salvo raras excepciones, ni par política ni un gobierno central que pudiese con su autoridad alcanzar todos los rincones del país, debiendo compartirlo con los centros locales de poder.

Asistíamos a una regionalización del poder a la que contribuyeron en gran medidi los caudillos con su concepción patrimonialista y paternalista del estado.

Era además, el Uruguay, un país no integrado, y no porque se presentaran grandes obstáculos en su geografía. La carencia de comunicaciones era tal que se convertía en tarea mas fácil comunicar a Montevideo con Londres o París que con las ciudadesy pueblos del interior de la República.

Un estado sin comunicaciones, sin recursos financieros para hacer frente a su presupuesto, sin policía ni escuelas, escasamente poblado (ver Apéndice - cuadro I), sin poder coactivo para hacer valer su autoridad, un estado incapaz para cumplir sus funciones esenciales, ¿era en realidad un estado?

La inseguridad en el medio rural fue la primera gran consecuencia de esta situación anómala impuesta por nuestra conformación socio-económica y la debilidad permanente del estado.

En medio de esta inseguridad, en un medio hostil, los vínculos entre los hombres van a actuar como substitutivos del ausente poder estatal. Los débiles recurren a la poderosos, éstos buscan su apoyo: nacen así relaciones de dependencia personal entre los grandes propietarios y los caudillos respecto a la peonada, los gauchos y hombres sueltos de nuestra campaña.

Será, por supuesto en las revoluciones, donde los lazos de dependencia personal : harán sentir con mas fuerza.

Pero esta estructura socio-económica se daba en un Uruguay que comenzaba "a sel penetrado por un estadio de civilización mas evolucionado, donde ingresaban form ${ }^{25}$ ? mentalidades capitalistas o modernas que se insertaban en una sociedad mas atrasada. $D$ la necesaria convivencia de estos dos sistemas que no pudieron vencerse uno al otro $p^{d}$ 
mucho tiempo, es que surgen las contradicciones regionales y sociales en el Uruguay de este período."1

Se abrían paso frente al viejo patriciado que actuaba como clase dirigente desde la época colonial y los estancieros-caudillos tradicionales, una nueva burguesía mercantil e industrial formada principalmente por inmigrantes enriquecidos y los modernos estancieros-empresarios, afincados sobre todo en el sur y en el litoral del río Uruguay donde están las tierras de mejor calidad. ${ }^{2}$

De este último grupo de estancieros que incluía a muchos de origen anglosajón y francés, saldrá la creación de la Asociacion Rural (1871), impulsora de la modernización del medio rural con el aumento de la explotación del ovino, la introducción del alambre, la mestización de las razas, etc.

No nos extrañará entonces que la inversión de capital exigida por el lanar convierta a las guerras civiles, al abigeo, al matreraje, en factores regresivos, en amenazas a la modernización.

Los estancieros nucleados en la Asociación Rural exigen seguridad y orden, regularización de la propiedad privada y también capitales para invertir en el campo, oponiéndose a la utilización del capital con fines especulativos y suntuarios como era lo corriente en el capital urbano.

Llegó así al poder el patriciado-principista (Presidencia del dr. José Ellauri: 1873-1875). Era la tradicional clase dirigente, doctoral, urbana y europeizada, arruinada paulatinamente durante las guerras civiles, carecía ya de fundamento económico. La fortuna estaba en otras manos.

Sin ataduras, entonces, con los propietarios de la tierra, ni con la burguesía dedicada al gran comercio importador, se sentían únicamente políticos, intelectuales puros, como en aquel momento sólo se podían dar en el París de la Tercera República.

Habían perdido contacto con la realidad del país: su comercio, su industria, su estancia. Se deslumbraron con los "principios" del liberalismo europeo. Educados en una universidad que sólo producía abogados, con programas de estudio "ideales" pero no reales, los doctores principistas bebieron su inspiración filosófica en la escuela que menos se adaptaba a las condiciones reales del país.

Pivel Devoto dice que los principistas al tener la posibilidad de gobernar incurrieron en dos errores fundamentales: "1. ${ }^{\circ}$ la sistemática desconfianza frente al Estado; $2{ }^{\circ} \mathrm{el}$ descuido consciente de los problemas materiales. Impregnados de un liberalismo absoluto, del individualismo antietático que fue uno de los rasgos político-sociales del siglo XIX, los principistas aplicaron en el Uruguay una desconfianza inexplicable. Ella en efecto podía comprenderse en un medio como el europeo, donde la libertad sólo podía triunfar venciendo a la tradición de estados fortalecidos por el autoritarismo de derecho divino o por el despotismo iluminado. Pero no tenía razón de ser en un medio como el nuestro, donde ni siquiera estaba formado aún el concepto de poder político. Luchando contra el fantasma de un estado absorbente, los principistas luchaban contra los clásicos molinos de viento. No aceptaban ni ejército de línea, ni bancos nacionales, ni garantías de ferrocarriles, ni el crédito del estado."3 
Era un liberalismo exacerbado luchando contra el molino de viento del estado uruguayo de 1870 .

Mientras se acentuaba la inseguridad del medio rural por la anarquía y el abigeo, los principistas se negaban a darle al débil estado los instrumentos necesarios para actuar.

Sufriendo la crisis económica de los años 70, el estanciero, colocado entre un estado ineficaz y una clase dirigente inoperante como eran los "principistas", tuvo como respuesta la agremiación en la ya nombrada Asociación Rural, convertida ahora en un grupo de presión a favor de un gobierno fuerte. Todo se puede sacrificar en el altar supremo del "orden". La anarquía engendró a Latorre.

\section{B) La educación}

La situación de la educación era penosa y luchaba con enormes carencias. No negamos el invalorable aporte que la iglesia realizó en esta materia. ${ }^{4}$

Tanto la escuela pública como privada eran católicas. La privada estaba en manos de órdenes religiosas generalmente. La pública que en el período colonial atendían los cabildos, de acuerdo a la Constitución de 1830 era competencia de las Juntas Econó. mico-Administrativas de cada departamento en los que se dividía la República. No había por lo tanto una educación de alcance nacional.

El informe Palomeque, elaborado en 1855, expresaba "que el país contiene 129.000 habitantes en la campaña, 30 escuelas y 899 educandos, o sea el 7 por mil."

Muchos pueblos carecían de escuela o preceptor, los maestros no tenían diploma, ni había textos y locales adecuados.

El gran atraso de la educación en la campaña se debía, en gran parte, al hecho de que el estado no pagaba los sueldos de los maestros y éstos abandonaban su profesión por otra mas lucrativa que les asegurase la subsistencia.

Por ejemplo: en 1870, en Cerro Largo, el atraso en el pago de los sueldos llegaba a 8 meses. Las escuelas se cerraban porque no se pagaban sus presupuestos.

Sobre el lamentable estado de la educación también nos informa la Memória de la Jefatura del departamento de San José (ciudad a sólo $90 \mathrm{~km}$ de Montevideo) del año 1879, cuando se iniciaba la aplicación de la reforma escolar de José Pedro Varela: "Existiendo en el Departamento 8.189 niños de 5 a 15 años sólo asisten a las escuelas 1.220 , o sea el $14 \%$ aproximadamente. Esa inmensa mayoría de niños que se cría sin recibir instrucción alguna se encuentra principalmente en la campaña y debe atribuirse ese mal no sólo a la incuria y abandono de sus padres, sino a las largas distancias y escasez de Escuelas Rurales.

En el distrito de las chacras de la $1 .^{\text {a }}$ sección policial que tiene una población de 5.024 habitantes no hay una sola escuela pública ni particular y por consiguiente no hay un sólo niño que reciba instrucción y es raro encontrar uno que sepa leer y escribir." 


\section{C) La iglesia}

Colonizada tardíamente la Banda Oriental durante el siglo XVIII, la iglesia uruguaya fue distinta a las del resto de América Hispánica desde sus orígenes.

Si bien se vivía un clima de unanimidad religiosa, la iglesia oriental era económicamente pobre, débil de estructuras, con escaso clero, la máxima jerarquía era un vicario apostólico instalado en Montevideo.

En la evolución de la iglesia uruguaya es necesario resaltar la figura del padre Dámaso Antonio Larrañaga (1771-1848). De los primeros exponentes del clero nacional, fundó la biblioteca pública en época de Artigas, como propulsor de la educación introdujo en 1821 y sostuvo durante todo el período de la Cisplatina, la Sociedad Lancasteriana, que aplicó el sistema de la enseñanza mutua. Suyo fue también el primer proyecto de creación de la universidad presentado en 1832, siendo senador de la República.

La figura de mons. Larrañaga, sacerdote ilustrado al modo de la España borbónica del siglo XVIII, hombre de Artigas, de la Cisplatina y del Estado independiente sucesivamente, llenó con su presencia el tránsito de la iglesia desde el período hispánico a la revolución, muriendo como el primer vicario apostólico (1832-1848) de un Uruguay nacido bajo el signo de una constitución liberal.

Terminada la "guerra grande", momento de ilusionada esperanza, el vicario apostólico mons. José Benito Lamas escribió el 28 de setiembre de 1854 una carta pastoral en la cual en sus recomendaciones finales a los presbíteros les decía: "Nuevamente os recomendamos, miréis por la integridad de vuestra vida, por la reforma de vuestras costumbres y por la mejora de la educación cristiana." ?

El año 1859 fue clave para la vida de la iglesia, en enero son expulsados los jesuítas y en mayo accede mons. Jacinto Vera al vicariato apostólico.

La década del 60 verá el estallido de la sorda lucha de tendencias dentro del catolicismo uruguayo: la corriente masónica y la corriente jesuítica, llamada por los masones "ultramontana".

Bajo la apariencia de un enfrentamiento entre la iglesia y el estado las dos tendencias se enfrentan dando lugar a la primera medida de secularización, la de los cementerios en 1861.

Vera, líder de la corriente pro-jesuítica en lucha con la masoneria, al ser desterrado a Buenos Aires por el gobierno del presidente Berro (octubre 1861 a agosto 1862) apareció como el derrotado, pero su regreso triunfal hirió de muerte al catolicismo masón que evoluciona filosóficamente hacia el racionalismo deísta de la religión natural.

$\mathrm{El}$ ataque a la iglesia ahora provendrá de allí. 


\section{II \\ EL MOMENTO HISTÓRICO}

Cuando el 10 de marzo de 1876 una comisión de ciudadanos alejados de la vida política, comerciantes muchos de ellos, se reúne en la plaza Matriz o de la Constitución y deciden encabezar una manifestación hasta la casa del cnel. Latorre para ofrecerle la suma del poder público, comienza una etapa fundamental en la historia de la República.

¿Qué había sucedido en este Uruguay todavía pastoril y caudillesco para que se llamara al poder a este militar profesional reservado y taciturno?

Los grandes caudillos orientadores de las "divisas" blanca y colorada habían muerto; los principistas, "los mejores hombres" por sus quilates intelectuales habían fracasado detrás de su liberalismo desenfrenado. Círculo brillante y estéril de universitarios, predicadores de libertades y derechos individuales, descuidaron los intereses nacionales provocando el desorden administrativo y la bancarrota financeira. Claro que no olvidamos que su prédica dejó plantadas las semillas de las libertades.

Pero las guerras civiles, la inseguridad, la ineficacia de los gobiernos, han cansado en exceso al pueblo que clama por orden, paz y seguridad.

El comercio pide el saneamiento de la moneda, la campaña seguridad para sus inversiones y su gente.

El llamado a Latorre aparece como la única solución a esta situación de vacío de poder. . " "este suceso no hace más que colocar las cosas en su centro. Latorre representa la única autoridad real del momento. El día que Latorre asume el poder, el oro baja ciento sesenta puntos. Este dato demuestra que la confianza pública está puesta en el nuevo gobierno; la Bolsa es el barómetro inequívoco de las situaciones. Una situación impuesta por un golpe militar, contra el orden y los intereses generales, provoca la baja de todos los valores, el retraimiento, y aún el pánico. El fenómeno contrario, prueba que la Dictadura de Latorre, al iniciarse su gobierno es, en efecto, $-\mathrm{y}$ aunque, en lo inmediato sea un simple gobierno militar - una imposición de las circunstancias, la solución fatal de los problemas políticos y sociales del momento." 8

\section{III}

\section{LATORRE, LA CREACIÓN DEL ESTADO MODERNO}

\section{A) El hombre}

Lorenzo de la Torre y Jampen nació en Montevideo en 1844 y murió en Buenos Aires, después de largo exilio, en 1916.

De origen modesto, sin posibilidad de realizar estudios superiores, muy pronto el joven Latorre se va a ver envuelto en las luchas de partido que asolaban el país.

Soldado en la revolución colorada del gral. Flores ${ }^{9}$ de la que salió subtenienth participó luego en la guerra de la Triple Alianza contra el Paraguay ${ }^{10}$ y en la represión de la revolución de "las lanzas" 11 . 
Hombre fuerte desde la caída del presidente Ellauri, ministro de Guerra y Marina, venció a la revolución "Tricolor" 12 dirigida por los "principistas" y se convirtió en el principal respaldo del presidente Pedro Varela (1875-76), político de segunda categoría formado a la sombra del gral. Flores, colorado "neto" o "candombero" como lo llamaban despectivamente los aristocráticos principistas ${ }^{13}$

Fueron las tratativas de Pedro Varela y su ministro de Hacienda Andrés Lamas con el banquero brasileño vizconde de Mauá, las que decidieron al cnel. Latorre a retirar el respaldo al presidente Varela, y a convertirse él mismo en gobernante.

En los días siguientes al 10 de marzo de 1876 las "fuerzas vivas" del país, comerciantes y hacendados le manifiestan con entusiasmo su apoyo, al que sigue el acatamiento del caudillo blanco Tímoteo Aparicio y el manifiesto beneplácito de las clases populares de Montevideo.

Latorre es el hombre de la hora. Sólo el "gremio de los doctores", los principistas, los intelectuales del momento, se le oponen.

\section{B) La obra}

¿Qué hace el cnel. Latorre desde el gobierno?

En primer lugar, diría, que crea un estilo propio de gobierno, nunca visto en el Uruguay: acción enérgica y mano fuerte, llama a los hombres mas capaces por encima de los partidos; "yo no puedo ni me propongo hacer un gran gobierno. Pero os respondo que haré un gobierno honrado y decente" ${ }^{14}$, dirá Latorre al sumir el poder, poder que ejercerá siempre con una austera eficacia.

Latorre es el ordenador del Uruguay. Construye caminos, puentes y vías férreas; sanea las finanzas; aumenta la producción y las exportaciones (ver Apéndice - cuadro III); se alambran las estancias (ver Apéndice - cuadro II), afirma con ello el derecho de propiedad, se acelera la mestización del ganado; hace habitable la campaña poniendo orden en ella; establece el principio de autoridad haciendo eficaz el brazo del estado; acerca la ciudad-puerto al campo-productor; realiza la unidad del país a la vez que lo moderniza y al modernizarlo lo prepara también para una mayor incorporación de su economía a las necesidades del mercado internacional dominado en ese entonces por Inglaterra $^{15}$

En otras palabras crea el estado moderno, ámbito necesario para el desarrollo de las "fuerzas vivas" del país, un país fortalecido que se aleja así de la influencia de sus vecinos, sobre todo del Brasil, sin que haya una prédica nacionalista ni un militarismo agresivo de su parte.

Pero además bajo el gobierno de Latorre y con su decidida colaboración se logra la reforma, casi diríamos la creación del sistema educativo nacional con la aprobación del decreto-ley de Educación Común inspirado por José Pedro Varela.

Y como si esto fuera poco por su directa intervención se erige la diócesis de Montevideo, fruto del renacer católico encabezado por la figura de mons. Jacinto Vera con quien nace la historia de la moderna Iglesia uruguaya. 
La relación de estos tres hombres, sus ideologías y sus realizaciones son nuestro tema.

\section{IV \\ VARELA, LA EDUCACIÓN DEL PUEBLO}

\section{A) El hombre}

En el Montevideo de la Guerra Grande, la "Nueva Troya" de Dumas sitiada por las fuerzas del gral. Manuel Oribe, nació en 1845 de hogar patricio José Pedro Varela.

Estudia en el colegio de los Escolapios, adolescente incursiona en la poesía, joven de 20 años escribe numerosos artículos en la "Revista Literaria": De la libertad de religión, De la libertad económica, De la libertad de bancos... son sus títulos.

Sobre la evolución del pensamiento filosófico de Varela nos dice Ardao: “Antes del viaje que realizara por Europa y Norteamérica de fines del 67 a fines del 68, Varela fue definido racionalista metafísico al modo de Francisco Bilbao, imbuído como este del cristianismo filosófico de Lamenais, Michelet, Quinet 'y Renan. Después de su viaje se encauzó poco a poco en el positivismo ciencista de Darwin y Spencer, que llegó a proporcionarle en la década del 70 su fórmula filosófica definitiva. Esas dos etapas de su evolución personal - de cuños francés una, de cuños sajón la otra - fueron dos etapas de la evolución intelectual del país en la segunda mitad del siglo XIX. En ambas él fue el verdadero iniciador." 16

En su trabajo sobre "Francisco Bilbao y el Catolicismo", Varela ya evidencia su actitud frente al catolicismo: "Y no nos cansaremos de repetirlo: son los restos de la educación católica que quedan entre nosotros, los que hacen posible el entronizamiento de las injusticias. Es por eso que combatir al catolicismo es combatir a la tiranía. Y es por eso también que Francisco Bilbao es uno de los apóstoles de la democracia y de la libertad."17

En 1867, Varela viaja por Europa y Estados Unidos, visita a Victor Hugo en París y al argentino Faustino Sarmiento ${ }^{18}$ en Washington a través del cual conoce la obra de Horacio Mann ${ }^{19}$.

A su regreso a Montevideo en 1868 comienza la prédica a favor de la educación del pueblo fundando con otros intelectuales "principistas" la Sociedad Amigos de la Educación Popular. ${ }^{20}$

Años después (1873) esta Sociedad va a provocar una carta pastoral de mons. Jacinto Vera a los curas párrocos acusando a la Sociedad de los educacionistas por $\mathrm{S} U$ manifiesto ateísmo.

En 1870 por su militante política contra el presidente Lorenzo Batlle, Varela es desterrado a Buenos Aires de donde regresa ese mismo año a su patria conmovida por la revolución de Timoteo Aparicio. 
Entre 1872 y 1876 Varela fue un activo "principista" con las características propias de toda esa generación de intelectuales.

Sin embargo, él que había sido precursos del racionalismo filosófico en 1865 se niega ahora a acompañar con su firma la Profesión de Fe Racionalista de 1872. Es que innovando por segunda vez consideraba al racionalismo superado orientando su pensamiento en la vertiente del positivismo.

En 1874 escribe La Educacion del Pueblo.

El fracaso principista de 1875 lo vuelve a Buenos Aires donde nuevamente se encuentra con Sarmiento. En setiembre del mismo año regresa a Montevideo.

\section{B) La obra}

Sus antecedentes políticos y su mentalidad liberal deberían haber hecho de Varela un opositor al gobierno autoritario del cnel. Latorre, como por otra parte lo fueron todos sus compañeros principistas.

Sin embargo el 27 de marzo de 1876 a propuesta del ministro de Gobierno José María Montero, amigo suyo, acepta el ofrecimiento de integrar la Comisión Extraordinaria Administrativa con el cargo de Director de Instrucción Pública.

Se inicia así la reforma vareliana de la educación. ${ }^{21}$

En sus obras La Educacion del Pueblo (1874) y La Legislacion Escolar (1876), Varela afirma que los cuatro principios que sostienen el movimiento de la educación popular son: universalidad, obligatoriedad, gratuidad y laicidad.

Hay una idea clave en el pensamiento de Varela: nuestra Constitución garantiza una democracia representativa, pero no hay verdadero gobierno del pueblo sin educación del pueblo. ${ }^{22}$

La República exige republicanos.

El sufragio supone un ciudadano consciente. ${ }^{23}$

No debemos confundir educación con instrucción. La educación debe desarrollar la entera naturaleza humana.

Cada ser humano es actor de su propia educación.

Educar y poblar es la consigna civilizadora del principismo.

Esto implica evidentemente, darle a la educación un poder transformador de la sociedad, la proyección por lo tanto de un "modelo nacional" 24 .

Pero el laicismo de este proyecto choca con la confesionalidad de la Constitución de 1830 (vigente hasta 1919) y por supuesto con la Iglesia Católica.

Para Varela este era un punto fundamental: la enseñanza religiosa conducía al desconocimiento de la libertad de conciencia, el Estado no debía comprometerse con ninguna religión y además el objetivo de la educación pública era formar ciudadanos y no incorporar al educando a una religión determinada. 

Estado.

"La escuela laica responde fielmente al principio de la separación de la Iglesia y el

Desde que vamos a sostener la justicia y la conveniencia de no enseñar en las escuelas públicas, o mejor dicho, de no enseñar en la escuela, los dogmas de una religión positiva cualquiera, empecemos por rechazar el cargo injusto que nos dirigen los adversarios, de esa doctrina, diciendo, que los que así piensan, quieren el establecimiento de la escuela antirreligiosa. No: como dicen los americanos, es un sectarian pero no godless: no pertenece exclusivamente a ninguna secta y, por la misma razón, no es atea, ya que el ateísmo es también una doctrina religiosa, por más absurda que pueda considerarse. . .

Ahora bien: entregar al clero la dirección de la enseñanza, no importa entregarle la dirección y el gobierno de la sociedad? En el dominio de la política, de la ciencia, del arte, no estará todo sometido al dogma, puesto que, en definitiva, el conocimiento de éste es el fin supremo a que aspira la Iglesia?

Así, el desconocimiento de la libertad de conciencia o la condenación a la ignorancia de los disidentes, es el primer mal de la enseñanza dogmática en la escuela: el sometimiento del Estado a la Iglesia es el segundo. . .

Pero, de las consideraciones precedentes se deduce acaso que sostengamos nosotros la necesidad de no enseñar religión alguna?

No, seguramente no. Con formas más o menos materiales, más o menos concretas, más o menos vagas, el sentimiento religioso vivirá siempre en el hombre, y el misterio de lo desconocido solicitará activamente los impulsos del alma humana. Pero la enseffanza religiosa debe dejarse a la familia y al sacerdocio.

La escuela tiene por fin desarrollar las fuerzas, físicas, morales e intelectuales del niño, dándole conocimientos útiles, desarrollando su inteligencia, preparándolo para la práctica de todas las virtudes y el cumplimiento de todos los deberes sociales. La Iglesia, soberana en su esfera, se reserva la transmisión de las verdades reveladas que constituyen el dogma. De ese modo se armonizan las exigencias del individuo como ser laico, y las de la sociedad; y las del individuo, como ser religioso y las de la Iglesia." 25

"Diversos objetivos pedagógicos perseguía el movimiento reformista - nos dice Arturo Ardao. Entre ellos estaba el de hacer laica nuestra enseñanza primaria, hasta entonces de invariable fundamento confesional católico. Fue el racionalismo bilbaíno (por el chileno Francisco Bilbao), iniciado en La década del 60, el que por vez primera sustentó en el país el principio del laicismo. El ambiente estaba, pues, preparado en la materia, cuando la campaña vareliana dio comienzo. En los años que siguieron, el incipiente positivismo del que el propio Varela fue pionero, reforzó desde otro punto de vista filosófico la corriente laicista promovida por la escuela del racionalismo metafísico.

Haremos abstracción aquí de las luchas laicistas sostenidas frente al Vicario Vera por la Sociedad Amigos de la Educación Popular. Nos limitaremos a establecer los $^{5}$ aspectos fundamentales del laicismo en el pensamiento y acción de Varela...

En 1876, designado bajo el gobierno de Latorre, Director de Instrucción Pública, formuló Varela un Proyecto de Ley de Educación Común. . En su proyecto dedicaba al problema de la enseñanza religiosa dos artículos: el 57, en el que establecía en lugar de 13 enseñanza de la religión católica la de los "principios generales de la Moral y Religión 
Natural"; y el 59, en el que, haciendo concesión al catolicismo ambiente, declaraba "facultativo de la Comisión de Distrito establecer en la escuela o escuelas del Distrito la enseñanza de la Religión Católica Apostólica Romana o del Catecismo Católico", dentro de determinadas condiciones, entre las cuales ésta: "Qué no podrá obligarse a ningún niño a que asista a la enseñanza de la Religión Católica o del Catecismo contra la voluntad o sin el consentimiento de sus padres, tutores o guardianes".

"Se explicaba Varela: "Si nos hubiéramos propuesto formular un proyecto de ley para la República ideal que, en sus horas de solaz, suele forjar también nuestra imaginación, habríamos suprimido el art. 59 y algunos otros; formulando una ley para nuestro país, que está lejos, y no poco, de ser una república ideal, hemos establecido lo que nos parece mejor en el terreno de lo posible, para el estado en que se encuentra actualmente." 26 Mayores concesiones todavía, deberá hacer Varela al catolicismo, como veremos.

Ya lanzado a la obra de la reforma, Varela enfrentará una triple polémica:

- La Iglesia Católica, dirigida por la fuerte personalidad del obispo de Montevideo Jacinto Vera, planteará su oposición a la eliminación de la enseñanza religiosa de las escuelas y a la filosofía liberal-materialista que encerraba el proyecto de Varela.

- Varela se enfrentará también con la Universidad a la que acusó de afrancesada (él admiraba el pensamiento anglo-norteamericano-protestante, acorde con su positivismo), dogmática, libresca y presuntuosa. Estos juicios provocaron la famosa polémica con el dr. Carlos María Ramírez. ${ }^{2}$

Polémica ésta entre el espiritualismo romántico y el positivismo evolucionista de Spencer y Darwin.

- El tercer enfrentamiento lo suscitaron los "principistas" al atacar a su ex-compañero por su actitud colaboracionista con el gobierno del cnel. Latorre.

Varela les responderá:

Se que mi actitud contribuye a prestigiar la dictadura, pero se también que si por este lado hago mal a mi país, por otro lado le hago bien. El prestigio que puedo dar a este gobierno es transitorio. El influjo de la reforma escolar es verdadero y profundo. ${ }^{28}$

Sabe también que en la medida que se eduque al ciudadano no podrá haber mas gobiernos como este.

El proyecto de Varela fue sometido al estudio de una comisión nombrada por Latorre donde sufrió importantes modificaciones.

Así el decreto-ley consagró la gratuidad y la obligatoriedad de la enseñanza, pero no la laicidad que originalmente había pretendido Varela.

Aunque él había propuesto una solución transaccional: mantener la enseñanza religiosa fuera del horario escolar con asistencia voluntaria, el decreto-ley dispuso en definitiva la obligatoriedad de la enseñanza de la religión católica excepto para los alumnos que profesaran otras religiones.

El artículo 19 del decreto-ley de educación común del 24 de agosto de 1877 decía: " $\mathrm{La}$ enseñanza de la religión católica es obligatoria on las escuelas del Estado, exceptuán- 
dose a los alumnos que profesen otras religiones y cuyos padres, tutores o encargados, se opongan a que la reciban".

La Iglesia rech zó esta fórmula aparentemente moderada, en cuanto hacía ingresar parcialmente en nuestra enseñanza primaria al principio laico. Este recién será consagrado integralmente en 1909.

Latorre no solo recogió la prédica de Varela sobre la enseñanza plasmándola en el decreto-ley de educación común, también dispuso que fuese él, el encargado de ponerla en hechos.

En una carrera contra el tiempo, moriría en octubre de 1879, Varela impulsó la "reforma" con estos criterios:

a) reforma de los programas educativos introduciendo lecciones sobre-objetos, dibujo, fisiología e higiene, física e historia natural, gimnasia y música.

b) incremento de centros docentes, llegando a mas de 300 escuelas al fin de su gestión y 14 cursos experimentales para adultos. (ver cuadros IV y V)

c) organizó el ejercicio del magisterio.

d) se introdujo la enseñanza mixta, es decir la co-educación de niñas y varones.

En otras palabras, en el escaso tiempo de tres años Varela puso en marcha la educación a nivel nacional.

\section{V \\ VERA, LA REORGANIZACIÓN DE LA IGLESIA}

\section{A) El hombre}

\section{Durán.}

El 3 de julio de 1813 en la isla de Santa Catalina (Brasil) nacía Jacinto Vera y Plata.

Sus padres, inmigrantes provenientes de las islas Canarias, viajaban hacia el Río de la

Hijo de una familia de humildes agricultores, desde su adolescencia se sintió inclinado al sacerdocio. Realizó sus estudios con las dificultades propias de la época en el Uruguay (no había por ese entonces Seminario ni Universidad), recibiendo las sagradas órdenes en 1841 en Buenos Aires.

Vuelto a su patria ejerció durante 18 años el curato de la parroquia de Canelones, pequeña ciudad situada en una zona agraria a $47 \mathrm{~km}$ de Montevideo.

Si bien Vera había recibido la influencia de los jesuítas en su formación, no era, sus largos años en Canelones lo demuestran, lo que llamamcs un "intelectual", era fundament talmente un pastor y un pastor de sólida ortoxia, sin los "contagios" liberales que evidenciará parte del clero en su polémico vicariato. 
En 1857 fallece el Vicario Apostólico de Montevideo monseñor José Benito Lamas, la máxima autoridad religiosa del Uruguay.

Su muerte repentina, en una peste de fiebre amarilla, provoca un interregno en el cual el gobierno presidido por Gabriel A. Pereira influído por la masonería ${ }^{29}$ y la Santa Sede discrepan respecto a la provisión de la vacante.

Preludio del conflicto de tendencias que va a estallar en la década del 60 .

Por fin, en 1859, es nombrado Vicario Apostólico monseñor Jacinto Vera. Su ascenso al vicariato marca una línea divisoria en la historia de la Iglesia uruguaya.

\section{B) La obra}

No olvidemos que en ese mismo año de 1859 el gobierno de Pereira había expulsado a los jesuítas del Uruguay. Todo un triunfo para la activa masonería.

Entre 1860-65 se produce la crisis del catolicismo masón. El conflicto entre Vera, cabeza de la tendencia llamada pro-jesuítica o ultramontana y la cristiano-masoneríaliberal "se resolvió - al decir de Ardao - con un triunfo de la tendencia jesuítica. Ese triunfo no sería ocasional, sino definitivo históricamente. El catolicismo masón, como tendencia organizada y militante sale del episodio herido de muerte". ${ }^{30}$

La mesonería deja de ser el sector "liberal" del catolicismo, Vera la obliga a definirse y así se va deslindando, se va convirtiendo no solo en una fuerza distinta sino también opuesta a la Iglesia.

Convertido ya en obispo de Megara "in partibus infidelium" (1864), Vera se dedica a reorganizar y fortalecer las débiles estrutucturas de la Iglesia uruguaya: "reformar al clero y moralizar al pueblo" es su lema.

Para realizar esto monseñor Vera pasa cada año meses enteros misionando en las ciudades y pueblos de la campaña. Vera evangelizando volvió a hacer a la Iglesia misionera. Quería construir la "cristiandad" que la época Colonial no había dado al Uruguay. ${ }^{31}$

La incansable actividad de Vera es resaltada aún por sus enemigos. "La Razón" a raíz de la aparición del diario católico "El Bien Público" en 1878 realizaba el siguiente comentario:

El catolicismo, estaba hasta hace poco en este país si no muerto, al menos completamente desprestigiado. Componían su apostolado una docena de sacerdotes nacionales poco ilustrados, hasta cierto punto liberales, y algunos sacerdotes extranjeros que con muy marcadas excepciones mas se preocupaban de adquirir medios de fortuna que de atender a la cura de almas. La iglesia vivía de las mezquinas pensiones que le asignaba el presupuesto, pobre, sin brillo, regenteada por un vicario que sabía hacerse respetar por su carácter afable, sus morales consejos y su pródiga caridad... Pero de repente, aprovechando circunstancias que no es del caso enumerar... emprende una campaña empeñosa para ponerse nuevamente en auge. Funda liceos, establece colegios y abandonando las estrechas columnas del periodismo, se lanza a las mas amplias del diario desde donde fulmina anatemas contra los no católicos, llegando en su intransigencia a pedir se corten las manifestaciones liberales invocando en su auxilio um artículo de la Constitución de la República. ${ }^{32}$ 
De la crisis interna la Iglesia salió fortalecida, apretados sus cuadros, pronta para enfrentarse con los enemigos de fuera: el racionalismo deísta, el positivismo materialista el liberalismo anticlerical. Filosofías todas provinientes del pensamiento europeo, que a través de la alienada y culta clase "doctoral" o "principista" irán como las olas a las rocas costeras, golpeando el edificio de la Iglesia.

Contemporáneamente, Pío IX en le encíclica "Quanta Cura" y en el Syllabus condenaba el panteísmo, el naturalismo, el socialismo, el comunismo, la moral autónoma y el liberalismo.

Después de 1870 el antagonismo entre el racionalismo y el catolicismo se manifestó en el choque de éste con la Universidad. Esa Universidad que como vimos simultá. neamente era criticada desde su positivismo por José Pedro Varela.

Sin embargo, como ya vimos, menor era el acuerdo entre Varela y la Iglesia. El positivismo y el espiritualismo tenían de común el anticlericalismo.

El espiritualismo ecléctico y la Iglesia compartían la defensa de la metafísima frente al positivismo.

Durante el gobierno del coronel Latorre la opinión pública se verá sacudida por la polémica que levantará el tema de la reforma escolar. Así lo relata, desde su óptica de historiador liberal, el dr. Eduardo Acevedo:

A la cabeza de todos los adversarios de la reforma escolar estaba el clericalismo que no perdonaba al reformador que hubiera establecido en su proyecto de Ley de Educación Común que el programa obligatorio solo comprendería los principios de moral y de religión natural y que sería facultativo de las Comisiones de distrito establecer también la enseñanza de la religión católica, pero a condición de darse fuera del horario de clase y sin carácter obligatorio para los niños. . Cuatro puntos fundamentales de la reforma escolar abarcaba la campaña clerical: la centralización técnica de la enseñanza, las escuelas mixtas, las Inspecciones departamentales y el programa escolar. ${ }^{33}$

Signo de esta oposición de la Iglesia, fue el proyecto del diputado e intelectual católico Francisco Bauzá, aprobado por la Cámara de Diputados a mediados de 1879 por el cual se suprimían la Dirección General y los Inspectores Departamentales, creándose en su lugar un Consejo encargado de adoptar textos y programas, se suprimían las escuelas mixtas y se reducía el programa de enseñanza a lectura, escritura, gramática, aritmética, geografía e historia nacional, Constitución, religión, dibujo y gimnasia. ${ }^{34}$

Años después, y es importante decirlo porque no se ha destacado suficientemente la obra positiva de Bauzá en esta materia, Bauzá "impulsó y orientó la obra del Instituto Pedagógico," el esfuerzo educacional "de mayor importancia realizado en el país por el sector privado, con una concepción espiritualista, realista y nacionalista de la educación en oposición a la enseñanza oficial, laicizante, enciclopedista y desteñida de sentido práctico que, desde 1877 , mantenía dividida nuestra sociedad." 35

Bauzá es muy claro al determinar la importancia de la trasmición de la fe católica ent la enseñanza: “. ... pero dígase lo que se quiera, sin creencias religiosas no hay pueblo $q^{\mathrm{Ul}}$ pueda vivir, ni nación que llegue a ser grande." 36

El problema de la reforma de la enseñanza nos mostró, entonces, a una Igles activa, coherente y dispuesta a la defensa de sus derechos, gracias en gran parte 
dinamismo de monseñor Vera y a la presencia de una generación de laicos comprometidos con la causa católica como lo fue Francisco Bauzá.

El 22 de julio de 1876 confluyeron tres personajes de nuestra historia en torno al problema educación: el obispo de Megara Jacinto Vera, el gobernador coronel Lorenzo Latorre y José Pedro Varela. Poco antes, pues, de que el gobierno de Latorre y los hombres de Iglesia uruguayos sacasen adelante la erección del obispado de Montevideo, 1878.

En esa fecha señalada del año 1876, Vera le escribía a Latorre. Vera estaba persuadido de los sentimientos que animaban al gobernador respecto a la religión católica. Presumía que no iba a poner el sello de su autoridad a disposiciones que menguasen los derechos de La Iglesia. Vera le llamaba la atención sobre el importantísimo problema educativo. Com ello desaba conservar la buena armonía que reinaba entre el Estado y la Iglesia. También procuraba que no cayese en el agravio de contribuir a atacar los intereses mas vitales de la santa religión. Porque el proyecto de Ley de Educación Común presentado por José Pedro Varela, Director de Instrucción Pública, en su parte dedicada a la enseñanza religiosa, comportaba un ataque a los derechos de la religión y de los católicos del Uruguay. Tal es la consideración que le sugería a Vera la lectura del artículo 59 del proyecto... Para el obispo la religión quedaba excluida del programa general de estudios. Por ahí se violaba la constitución de la república y se atacaba a la religión católica. Los legítimos derechos de la religión católica no podían quedar librados al parecer de una comisión vecinal.

Si bien Vera se dirigía oficialmente al ministerio de Gobierno sobre este asunto, con todo quería llamar la atención del gobernador provisorio, para que sintiese la voz del prelado católico y del amigo. Vera esperaba en esta ocasión como lo había experimentado en otras, que Latorre se mostrase deferente a sus justas y razonables indicaciones.

En una encrucijada importante de la historia de la educación en el Uruguay el documento referido entrelazó a tres personalidades: Latorre, Vera y Varela. ${ }^{37}$

\section{VI CONCLUSIONES}

En este clima intelectual de enfrentamiento del positivismo y el espiritualismo católico transcurrirá el constructivo gobierno del coronel Latorre (1876-1880).

Intensas fueron sus relaciones tanto con Vera como con Varela. Cuál fue su actitud frente a estos dos hombres portavoces de filosofías antagónicas?

Ya vimos como puso su decisión y todos los medios de su gobierno para que José Pedro Varela pudiera concretar sus ideas reformistas en la educación. Fruto de esta colaboración entre la idea y el poder fue el Decreto-ley de Educación Común de 1877.

Tanto fue así que no hubiera habido un Varela reformador, sin la voluntad de un Latorre gobernante.

Quiere decir esto que Latorre compartía el pensamiento filosófico de Varela en todos sus términos?

Aportemos algunos elementos de juicio.

Sobre sus creencias personales digamos que Latorre se consideraba católico. En carta que envía al Nuncio en Río de Janeiro cuando tramitaba la creación de la diócesis, escribe: 
No dejará S.S. Illma. de reconocer que el interés que como gobernante y como ciudadano de la República tengo en la consecución de aquella prerrogativa para nuestra Iglesia, nace de los sentimientos católicos que profeso y que constituyeron siempre el culto de mis padres... 38

Respecto a sus actitudes como gobernante podemos decir que las relaciones entre $b_{a}$ Iglesia y el Estado fueron siempre de cordial colaboración.

Eduardo Acevedo afirma que el ambiente oficial de la época era propicio a la Iglesia. Por ejemplo, el ejército concurría frecuentemente a la iglesia para oir misa o para solemnizar las funciones eclesiásticas, también obligó a los comercios a respetar el domingo como día de descanso y hasta hizo que los espectadores de la procesión de Corpus Christi se sacaran el sombrero a su paso.

Y esta actitud de apoyo a la Iglesia se evidencia también en lo que respecta a la educación. Veamos la solución que Latorre da al espinoso problema de la laicidad. Evidentemente al rechazar el artículo 59 del proyecto de ley de Varela y hacer aprobar el artículo 19 del decreto-ley de Educación Común (cf. p.25), Latorre se inclina por una solución que indica respeto de lo que la Iglesia considera sus derechos en ese momento.

Y esto apoyo a los derechos de la Iglesia se extiende tanto a la polémica previa a la aprobación de la Reforma como a la aplicación posterior. ${ }^{39}$

Es necesario recordar, además, que si bien los intelectuales principistas fueron los mas encarnizados enemigos de Latorre negándose a colaborar con él, con la solitaria y criticada excepción de José Pedro Varela, en cambio las figuras mas prominentes del laicado católico, el poeta Juan Zorrilla de San Martín y el historiador Francisco Bauzá colaboraron en su gobierno integrando junto con el presbítero dr. Mariano Soler [futuro arzobispo] las Cámaras de 1879 elegidas para constitucionalizar el poder de Latorre. Esto no quiere decir que Bauzá y Zorrilla no criticaran al gobierno cuando de acuerdo a sus conciencias lo creían necesario.

Dentro de este espíritu de colaboración debemos destacar la erección de la diócesis de Montevideo, primera del Uruguay, el 13 de julio de 1878.

Unida la Iglesia y el Estado por la Constitución de 1830, el ya viejo deseo de organizar la jerarquía del país había naufragado repetidas veces ya fuese por desinterés, por la estrechez de la hacienda pública o mas recientemente por los embates del racionalismo librepensador y del positivismo materialista.

Aquí también, como en el caso de la reforma escolar, Latorre pone toda su eficacis y empeño en la realización de los trámites necesarios para la erección de la primera diócesis. $^{40}$

Y si a esto le sumanos la donación de tierras públicas para construir templos $y^{18}$ creación de los tribunales eclesiásticos, nos preguntamos: Esta manifiesta armonía entre la Iglesia y el Estado, cuando ya la clase dirigente se alejaba del catolicismo, nos hará ver en Latorre a un gobernante clerical al estilo de su casi contemporáneo García Moreno de Ecuador?

Sin embargo no podemos aplicar para el Uruguay el esquema liberales-anticlericale frente a conservadores-católicos que sí responde a la realidad de muchas nacione americanas del período. 
A muchos llama la atención que el mismo Latorre fuera el autor del Registro de Estado Civil (ley del 11.2.1879) que secularizaba los registros de nacimientos, matrimonios y defunciones que llevaban las parroquias. En este sentido Latorre se inscribe en el proceso secularizador que comenzando con Berro llega hasta Batlle y Ordóniez, culminando en el primer cuarto del siglo XX.

Pero también nos llama la atención de que esta medida secularizadora prácticamente no levantó resistencias en la Iglesia. La armonía continuaba.

Sería Latorre un pragmático-realista que aceptaba cualquier sugerencia que reportara prestigio a su acción de gobierno? Actuaba simplemente como un moderador de fuerzas en pugna?

Pienso que no fue así, ni maquiavelo ni simple árbitro.

Latorre tiene un plan nacional: organizar al país. Por supuesto que es un realista, él no lucha contra molinos de viento como los principistas. Organizar significa modernizar las estructuras de la República, esto es lo que hace en lo económico y en las comunicaciones. Organizar, también significa reafirmar la soberanía tantas veces en peligro en el pasado.

Latorre es intelectualmente un hombre de fondo católico, pero necesita a Varela un liberal laicizante para hacer la reforma escolar, pero eso sí, sin laicismo.

De ahí sus "podas" al proyecto original de Varela.

Latorre ve que no hay nación, unidad nacional, sin una educación nacional. Por eso se preocupa tanto de la enseñanza del español en las zonas de frontera con el Brasil.

Por otra parte Latorre siente la fuerza moral de la Iglesia, ve la dignidad del Uruguay menoscabada por la ausencia de jerarquía eclesiástica, como si fuese un país de misión.

La independencia eclesiástica va unida a la independencia política.

El Uruguay debe lograr su plena autonomía religiosa, con su diócesis, su obispo y sus tribunales eclesiásticos.

Pero además, sin duda que Latorre tiene en cuenta que la Iglesia es un componente esencial del ser nacional, es factor aglutinante y moralizador de las costumbres. Y Latorre está empeñado justamente en hacer habitable la campaña para las familias persiguiendo a los elementos inadaptados a la vida social organizada.

Acaso Latorre no verá necesario fortalecer a la Iglesia que sufre los embates del liberalismo anticlerical?

No habrá sido la creación de la diócesis de Montevideo una respuesta al decretoley de Educación Común propiciado por Varela?

Lo que es un hecho es que Latorre respaldó efectivamente a monseñor Vera y a la Iglesia, y que con la erección de obispado le dio la unidad de autoridad necesaria y el prestigio para hacer frente a la dura lucha que los años siguientes le deparaban.

Reúne así el gobernante los esfuerzos de dos de las mentes mas enérgicas y lúcidas, aunque opuestas, como lo eran Jacinto Vera y José Pedro Varela. Y a ambos respalda, aunque como vimos en distinta medida. 
En gran parte por su decidida actitud el lustro decisivo para la organización del Uruguay moderno que va de 1876 a 1880 , fue también un lustro fundamental tanto para la educación como para la Iglesia.

\section{APENDICE}

\section{Cuadro I \\ POBLACION DEL URUGUAY}

$\begin{array}{rrr}\text { AÑO } & \text { TOTAL } & \text { MONTEVIDEO } \\ & & \\ 1830 & 74.000 & 14.500 \\ 1852 & 131.969 & 34.000 \\ 1872 & 420.000 & 105.000 \\ 1878 & 438.245 & 111.500 \\ 1881 & 460.000 & 164.000\end{array}$

Fuente: ACEVEDO, EDUARDO - Anales Históricos del Uruguay, tomos III y IV.

\section{Cuadro II \\ IMPORTACION DE ALAMBRE Y ESTANCIAS ALAMBRADAS (1872-82)}

$\begin{array}{ccc}\text { AÑO } & \begin{array}{c}\text { IMPORTACION } \\ \mathrm{kg}\end{array} & \begin{array}{c}\text { ESTANCIAS } \\ \text { ALAMBRADAS }\end{array} \\ & & \\ 1872 & 2.050 .250 & 123 \\ 1873 & 1.847 .951 & 111 \\ 1874 & 2.476 .023 & 149 \\ 1875 & 2.140 .835 & 129 \\ 1876 & 2.150 .000 & 129 \\ 1877 & 6.646 .743 & 401 \\ 1878 & 6.674 .977 & 402 \\ 1879 & 10.290 .295 & 620 \\ 1880 & & 902 \\ 1881 & 19.642 .000 & 1.185 \\ 1882 & 12.502 .800 & 755 \\ & & 4.906\end{array}$

Fuente: BARRAN, J.P. Y NAHUM, B. - Historia Rural del Uruguay Moderno, tomo 1. 


\section{Cuadro III \\ AUMENTO DE ALGUNOS RUBROS DE EXPORTACION}

$\begin{array}{ccc}\text { AÑOS } & \begin{array}{c}\text { LANA Y CUEROS LANARES } \\ \mathrm{kg}\end{array} & \begin{array}{c}\text { HARINA Y TRIGO } \\ \text { Ton. }\end{array} \\ 1875 & 12.235 .000 & 155 \\ 1877 & 20.605 .000 & 9.081\end{array}$

Fuente: PIVEL DEVOTO, J.E. Y A. RANIERI DE PIVEL - Historia de la República Oriental del Uruguay.

\section{Cuadro IV \\ EVOLUCION DE LA ENSEÑANZA PRIMARIA}

$\begin{array}{ccccc}\text { AÑ̃ } & \begin{array}{c}\text { ESCUELAS PUBLICAS } \\ \text { MONTEVIDEO }\end{array} & \text { INTERIOR } & \text { TOTAL } & \text { ALUMNOS } \\ & & & & \\ 1860 & 14(1.118 \text { alums.) } & 58 & 72 & - \\ 1871 & 42(4.851 \text { alums.) } & - & - & 15.000 \\ 1876 & 62(9.070 \text { alums.) } & 134 & 196 & 17.541 \\ 1878 & - & - & 259 & 19.669 \\ 1879 & - & - & 298 & 23.281\end{array}$

(Cuadro del autor en base a datos parciales) 


\section{Cuadro V \\ ASISTENCIA A LAS ESCUELAS}

(A)

AÑO

1877

1878

1879

1880

\author{
ESCUELAS
}

196

259

298

310

\section{INSCRIPTOS}

17.541

19.669

23.281

24.785

\section{ASISTENCIA MEDIA}

\author{
12.361
}

15.035

17.304

18.398

(B)

\begin{tabular}{|c|c|}
\hline \multicolumn{2}{|c|}{ AÑO: 1878} \\
\hline Niños en edad escolar & $=106.255$ \\
\hline En las escuelas publicas & $=19.669$ \\
\hline En las escuelas privadas & $=13.226$ \\
\hline Sin recibir educacion & $=73.361=69 \%$ \\
\hline
\end{tabular}

Instituto Nacional de Docencia

Montevideo - Uruguai

\section{NOTAS}

${ }^{1}$ Barrán, José P. y Nahum, Benjamín: Historia Rural del Uruguay Moderno. Tomo 1, Montevideo, 1970, p.140.

${ }^{2}$ La llegada de inmigrantes al Uruguay (españoles, italianos, ingleses, franceses) comenzó a hacerse evidente durante la Guerra Grande, período en cual Montevideo llegó a tener mas habitantes extranjeros que orientales.

${ }^{3}$ Pivel Devoto, Juan E. y Ranieri de Pivel Devoto, Alcira: Historia de la Republica Oriental del Uruguay. Montevideo, 1966, pp.334 y 335.

${ }^{4}$ En su documentado trabajo el dr. Juan Villegas S.J. nos dice: "Los jesuítas regresaron 2 Uruguay el 3 de setiembre de 1872. Fundaron una residencia en Montevideo. Proyectaban crear un colegio y aún un colegio seminario como finalmente lo hicieron en el año 1880 .

La actividad de la Iglesia en materia educativa se enriquecía en esta segunda mitad del siglo cos la venida de estos religiosos; con la enseñanza impartida por las hermanas salesas en Montevideo; la de los padres bayoneses; las hermanas del Huerto, y los salesianos. Parecía como que la Iglesia rescatara de su pasado colonial ese valioso ayudarse de las congregaciones religiosas para prestar servicios educts tivos.

Ya en la década del setenta, el mundo católico del uruguayo se encontraba enfrentado con 1 gran polémica sobre la educación católica. Nunca hasta entonces había existido un tan claro planteo ds posiciones. 
La polémica se suscitaba en momentos en que la Iglesia hacía esfuerzos por ofrecer enseñanza católica, valiéndose sobre todo del elemento especializado representado por los religiosos. Pero no jebe olvidarse que el proceso lento que vez desterró a la escolástica de la Universidad liberalizó a los rupos dirigentes del país. Por ahí vendrá el otro paso a través de la ley sobre Instrucción Pública que eparará Iglesia de educación estatal." Villegas S.J., Juan: La actividad educativa de la iglesia en el Uruguay hasta Jose Pedro Varela, en Revista Punto 21, vol.3, n. ${ }^{0}$ 2, Montevideo, 1977, pp.56 y 57.

${ }^{5}$ Informe Palomeque - 1855 , Consejo Nacional de Educación, Cuaderno de Divulgación n. ${ }^{\circ} 1$, Montevideo, 1974, p.19.

${ }^{6}$ Pivel Devoto, Juan E. y Ranieri de Pivel Devoto, Alcira: op. cit., pp.348 y 349.

${ }^{7}$ Tomé, Eustaquio: El vicariato apostolico de Don Jose Benito Lamas (1854-1857), Revista Histórica, n. ${ }^{\circ} 37$, Montevideo, 1941, p.147.

${ }^{8}$ Zum Felde, Alberto: Proceso historico del Uruguay. Montevideo, 1967, pp.208 y 209.

${ }^{9}$ La revolución del caudillo Flores, llamada también “cruzada libertadora" (1863-65) estaba dirigida contra el gobierno "fusionista" de Bernardo Berro, con la radicalización de la lucha terminó siendo una nueva guerra civil entre blancos y colorados. Flores contó con el apoyo de Mitre y del Brasil. Esta misma alianza se repetirá en la guerra contra el Paraguay.

${ }^{10}$ En la guerra de la Triple Alianza se formaron los cuadros del ejército profesional uruguayo.

${ }^{11}$ Esta revolución (1870-72) se llamó así porque las lanzas fueron todavía las armas mas usadas. Fue dirigida por el caudillo blanco Timoteo Aparicio contra el gobierno colorado "exclusivista" del gral. Lorenzo Batlle. Terminó con el primer acuerdo de coparticipación entre los blancos y los colorados.

12 Llamada así porque pretendía reunir a los principistas blancos y colorados.

13 No es pariente de José Pedro Varela, el educador.

14 Citado en Pivel Devoto, Juan y Ranieri de Pivel Devoto, Alcira: op. cit., p.346.

15 Inglaterra reanudó relaciones precisamente con el gobierno de Latorre.

16 Ardao, Arturo: Racionalismo y Liberalismo en el Uruguay. Montevideo, 1962, pp.225 y 226.

${ }^{17}$ Varela, José Pedro: Francisco Bilbao y el Catolicismo. "El Siglo" del 24 de noviembre de 1866, Montevideo.

${ }^{18}$ Domingo Faustino Sarmiento, que mas adelante será presidente de la Argentina, había publicado en 1866: Las escuelas base de la prosperidad en los Estados Unidos.

19 Varela y Sarmiento eran admiradores fervorosos de los Estados Unidos lo que contradecía la tendencia dominante en las clases cultas del Río de la Plata que seguían el modelo francés. La reforma educacional propuesta por Varela se debe, "mas bien, al ya creciente influjo del Positivismo ciéntifico en las corrientes filosóficas y culturales de la época; y mas directamente, al ejemplo del Positivismo pedagógico norteamericano, en cuyo ambiente recibió Varela la poderosa influencia que determinó su vocación y su apostolado."Zum Felde, Alberto: op. cit., pp. 265 y 266.

20

" $\mathrm{El}$ movimiento liberal - es decir, el movimiento tendiente a combatir la influencia religiosa en cultura y fundar toda doctrina y toda educación sobre bases puramente racionales - es, en efecto, ${ }^{u}$ o de los hechos mas significativos en la evolución intelectual del país; ... su punto de arranque Puede establecerse en la fundación de la Sociedad Amigos de la Educación Popular, que presidía el dr.

Elbio Fernández y de la que era activísimo miembro José Pedro Varela. .

Constituída en el 68 , la Sociedad - cuyo programa declarado, coincidente con la próxima reforma vareliana, era la fundamentación racionalista de la enseñanza, de acuerdo con los conceptos Fentíficos del siglo - fundó la primera escuela que luego llevó el nombre de su iniciador: Elbio "rnández, muerto tempranamente, al igual que su amigo y continuador José Pedro Varela. Durante Al unos años, fue esta escuela el mas acreditado centro de instrucción de la República." Zum Felde, Proceso Intelectual del Uruguay, tomo 1, Montevideo, 1967, pp.172 y 173. 
21 El de Varela no es el primer proyecto, ya el 9 de mayo de 1873 el diputado blanco-principista Agustin de Vedia había presentado al Poder Legislativo un plan de reorganización total de la enseñanza, antecedente inmediato al proyecto de Varela: "El extenso articulado del plan Vedia partiendo del principio de la enseñanza gratuita e igualitaria, postula la creación del Instituto de Instrucción Pública y del Departamento general de escuelas, prevé las rentas escolares propias en base a la contribución directa, propone la fundación de institutos normales, de Inspecciones y Juntas Vecinales, de colegios de enseñanza superior y cursos complementarios de enseñanza agrícola industrial. . reglamenta el funcionamento de los colegios de enseñanza superior, las sesiones generales del magisterio y las bibliotecas escolares.

... El artículo 75 del proyecto de Vedia, referente a la prohibición de la enseñanza religiosa en las escuelas, reanudó el pleito latente entre nuestro racionalismo espiritualista y el catolicismo escolástico. Monseñor Jacinto Vera, portavoz oficial del clericalismo, se dirige a la Cámara pidiendo la desaprobación del Cuerpo Legislativo al Proyecto de Enseñanza. Nuevamente "El Siglo", estandarte del liberalismo racionalista, objeta los reclamos del catolicismo: "La enseñanza religiosa en las escuelas públicas es un ataque à la libertad de aprender y à la libertad de enseñar. . El Estado enseñando en sua escuelas una religión determinada se convierte en propagandista de una creencia religiosa y al hace lo extralimita sus facultades. . . la misión del Estado no es la de imponer tal ó cual religión. .. tal ó cual dogma, sino la de garantir la libertad de todos para respetar la libertad que tiene todo hombre de adorar á Dios según su conciencia. .." Con el proyecto de Vedia y su sonado debate parlamentario y periodístico se ajustan criterios definitivos en materia de enseñanza religiosa." Oddone, J.A.: $E l$ Principismo del Setenta. Montevideo, 1956, pp.153 a 155.

${ }^{22}$ Al respecto nos dice Varela: "La escuela es la base de la República. Sin ella podrán vivir y sostenerse los gobiernos despóticos: pero las democracias sólo encontrarán el desquicio, el caos, mientras no eduquen el caos... Debido á la falta de educación de nuestras masas éstas permanecen generalmente ajenas á todos los movimientos de opinión que se operan entre nosotros. Sólo las pequeñas facciones del país que se llaman clases elevadas, se agitan y piensan. El resto permanece estraño á todo; sordo lo mismo al rugido de las tormentas revolucionarias que á la dulce armonía de las grandes doctrinas que suclen llegar hasta nosotros..." Varela, José Pedro: La educacion del puebla. Montevideo, 1973, p.40.

23 "La ignorancia bajo $\mathrm{H} l$ despotismo produce ese orden enfermo que Alfieri llamaba una vida sin alma: bajo la república, incuba y produce los motines, las asonadas, las revuestas constantes, la violación de las lzyes, el falseamiento de las instituciones, la anarquía erigida en gobierno, en una palabra el caos ocultándose bajo el título y las formas aparentes de las instituciones libres...

Para establecer la república, lo primero es formar los republicanos: para crear el gobierno del pueblo, lo primero es despertar, llamar a la vida activa, al pueblo mismo: para hacer que la opinión pública sea soberana, lo primero es formar la opinión pública.. .

El sufragio universal supone la conciencia universal, y la conciencia universal supone y exige ls educación universal. Sin ella la república desaparece, la democracia se hace imposible y las oligarquías, disfrazadas con el atavío y el título de república, disponen a su antojo del destino de los pueblos. . Varela, José Pedro: op. cit., pp. 42 y 43.

24 "Varela se enfrentó así, necesariamente, con el más agudo y candente problema uruguayo de aquel momento histórico: el estado de semibarbarie política que en el país se debatía, - fluctuando desequilibrio entre la anarquía y el despotismo - sin que pudiera hacer se efectivo el imperio de la instituciones republicanas, ni asentarse el orden jurídico cuya base es la libertad, ni organizarse Estado sobre la firmeza del orden, que permite el desarrollo de la riqueza pública, el progres civilizador y la cultura general de la masa.

Corresponde a Varela el honor de haber sido el primer intelectual uruguayo que estudió cofi criterio positivo los problemas de la realidad sociológica nacional, procurando desentrañar las causas de nuestro fenómenos y establecer los medios de curar nuestros males." Zum Felde, Alberto: op. cit p. 271 .

25 Varela, José Pedro: op. cit., pp.57 a 62. 


\section{Ardao, Arturo: op. cit., pp. 278 a 280.}

${ }^{27}$ En esta polémica Varela dirá: “. . . se sabe que es la falta de sentido práctico lo que caracteriza a lso graduados universitarios." Había en esta clase universitaria que formó la generación del "principismo" del 72 no solo un desprecio hacia los aspectos materiales y económicos propio en mayor o menor grado de todo intelectual "puro", sino también una actitud soberbia frente al pueblo, un desprecio a "la canalla" que le hace decir a Varela que estaba frente a la "... tendencia oligárquica de una clase que se cree superior”. Jose Pedro Varela; Carlos Maria Ramirez: El destino nacional y la universidad. polemica. Biblioteca Artigas. N. ${ }^{\circ} 67$ y 68.2 tomos, Montevideo, 1965.

${ }^{28}$ Citado en Acevedo, Eduardo: Anales historicos del Uruguay. Tomo IV, Montevideo, 1933, p. 97.

${ }^{29}$ Según Arturo Ardao después de 1850 hay un renacimiento de la franc-masonería del Uruguay integrada por dos corrientes que dependen del exterior: "Por un lado, la logia francesa "Les Amis de la Patrie", de existencia continua y activa desde 1842, se hallaba organizada de acuerdo con el Rito Moderno o Francés, y dependía del Gran Oriente de Francia. Por otro lado, un conjunto de logias nacionales que surgen y proliferan entonces, al parecer no totalmente desvinculadas de las logias nacionales de épocas anteriores; se hallaban organizadas de acuerdo con el Rito Antiguo o Escocés, y dependían del Gran Oriente del Brasil." op. cit., pp.137 y 138.

${ }^{30}$ Ardao, Arturo: op. cit. p.188.

${ }^{31}$ España no llegó a establecer en la llamada Banda Oriental del Uruguay esa cristiandad indiana que vieron florecer otras partes de América, debido fundamentalmente a la tardía ocupación efectiva que hicieron de este territorio en el sigio XVIII. Mientras la mayoría de las capitales americanas son del siglo XVI, Montevideo recién será fundada en 1726; y mientras el período colonial duró tres siglos en gran parte de América, esta Banda Oriental, como las Californias en el norte eran adquicisiones recientes en las "fronteras" del Imperio.

32 Citado en Acevedo, Eduardo: op. cit., pp. 30 y 31.

${ }^{33}$ Acevedo, Eduardo: op. cit., p.113.

${ }^{34}$ Entre los muchos puntos vulnerables que Bauzá encuentra al sistema vareliano queremos destacar: a) el enciclopedismo de la enseñanza. "Las escuelas de primer grado ú elementales, no deben enseñar, ni tantas matérias que confundan al estudiante, ni tan pocas que esterilicen el tiempo empleado en aprenderlas. . . La eficacia de esta educación primaria consiste en que ella sea dada en el mas corto plazo, a fin de aprovechar el tiempo y no fatigar al estudiante..." b) el desarraigo y la falta de espíritu nacional. Destaca Bauzá que el texto de historia "que corre con mas aplauso en las escuelas" es el Bosquejo Historico de Francisco Berra, este libro responde a la tesis de Sarmiento de que la historia de los países del Plata es una dialéctica entre civilización y barbarie. Como la primera reside en la ciudad y la segunda en la campaña y nuestra revolución surgió del medio rural conducida por los caudillos, "en este precioso librito - dice Bauzá - resulta probado que Artigas, el fundador de nuestra nacionalidad, era un bandido; que Lavalleja, el reivindicador de nuestra independencia, era un mísero gaucho sin carácter ni moralidad propia; que Rivera, el jefe de la democracia uruguaya, vencedor del Rincon y de Cagancha, era un salteador de caminos... El pundonor nacional, base de toda enseñanza séria para la juventud, brilla por su ausencia en el programa de educación que ellas disciernen. . Como instrucción historial, tenemos la creencia generalizada por los textos escolares, de que nuestra ascendencia nacional entronca con una caravana de bandidos." c) "La situación legal de la instrucción pública en el país, es la de un monopolio encaminado a destruir metódicamente todas las iniciativas particulares." Bauzá, Francisco: Estudios Constitucionales, Montevideo, 1887, pp.223 a

${ }^{35}$ Pivel Devoto, Juan E.: Francisco Bauza. tomo 1. ${ }^{\circ}$, Montevideo, 1968, p.272.

36

Bauzá, Francisco: op. cit., p. 264.

37

Villegas S.J., Juan: op. cit., pp. 57 y 58.

38

Citado en De Salterain y Herrera, Eduardo: Latorre. La Unidad Nacional. Montevideo, 1975, pp. 343 y 344 . 
${ }^{39}$ Nos relata Eduardo Acevedo: "El clericalismo. . conseguía abrir-se camino no solo en la Cámara de Diputados, sino en la misma prensa oficial. "La Nación", diario latorrista ultra, acompañaba esa prédica demoledora con editoriales en que se pedía la supresión de las Inspecciones Departamentales y se combatían las teorías del reformador, "que podían ser apropiadas, decía el articulista, para otros pueblos que no hayan tenido nuestro mismo origen ni nuestra tradición." $\mathrm{Y}$ también: "Con motivo de algunas visitas escolares realizadas por el Inspector Departamental de Montevideo dictó el coronel Latorre un decreto por el que establecía que tratándose de escuelas dirigidas por Hermanas de Caridad debería limitarse el Inspector "a la simple toma de datos estadísticos proporcionados por las respectivas directoras y a cerciorarse de si enseñaba el idioma castellano con preferencia a otro." "Esta disposición, agregaba el decreto, en nada contraría el espíritu de las leyes vigentes, concurriendo por el contrario a hacer efectivo el principio de la libertad de enseñanza consagrado en esas mismas leyes."

Quedaban por lo tanto las escuelas religiosas - comenta Acevedo - fuera de la esfera de acción de las autoridades escolares." Acevedo, Eduardo: Op. cit. tomo IV, pp.114 y 147.

${ }^{40}$ Tal es el interés de Latorre que el Internuncio en el Río de la Plata, monseñor Angel di Pietro, en correspondencia con el presbítero dr. Soler verifica complacido que "el gobierno está loablemente impaciente por alcanzar sin demora esta gracia", y toma en cuanta "el laudable apremio con que urge el asunto." Vidal, José María: El primer arzobispo de Montevideo Dr. Don Mariano Soler. Tomo I, Montevideo, 1935, p.80. 